\title{
SIMULATING GREAT LAKES WATER LEVELS FOR EROSION PREDICTION
}

\author{
by \\ Todd L. Walton, Jr. \\ Coastal Engineering Research Center \\ DEPARTMENT OF THE ARMY \\ Waterways Experiment Station, Corps of Engineers \\ 3909 Halls Ferry Road, Vicksburg, Mississippi 39180-6199
}

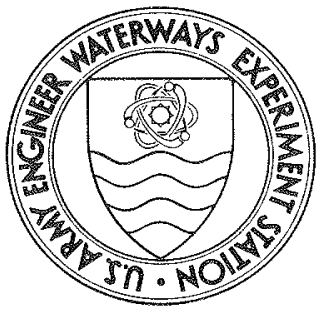

August 1990

Final Report

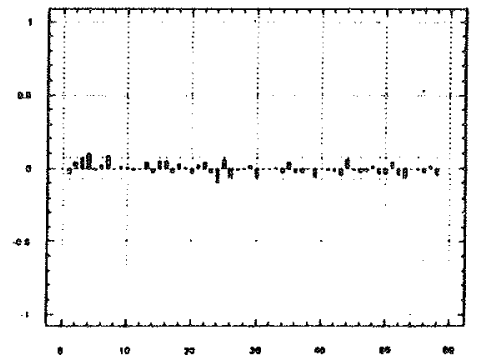

Approved For Public Release; Distribution Unlimited

Prepared for DEPARTMENT OF THE ARMY

US Army Corps of Engineers

Washington, DC 20314-1000 
When this report is no longer needed return it to the originator.

The findings in this report are not to be construed as an official Department of the Army position unless so designated by other authorized documents.

The contents of this report are not to be used for advertising, publication, or promotional purposes. Citation of trade names does not constitute an official endorsement or approval of the use of such commercial products. 
Unclassified

SECURITY CLASSIFICATION OF THIS PAGE

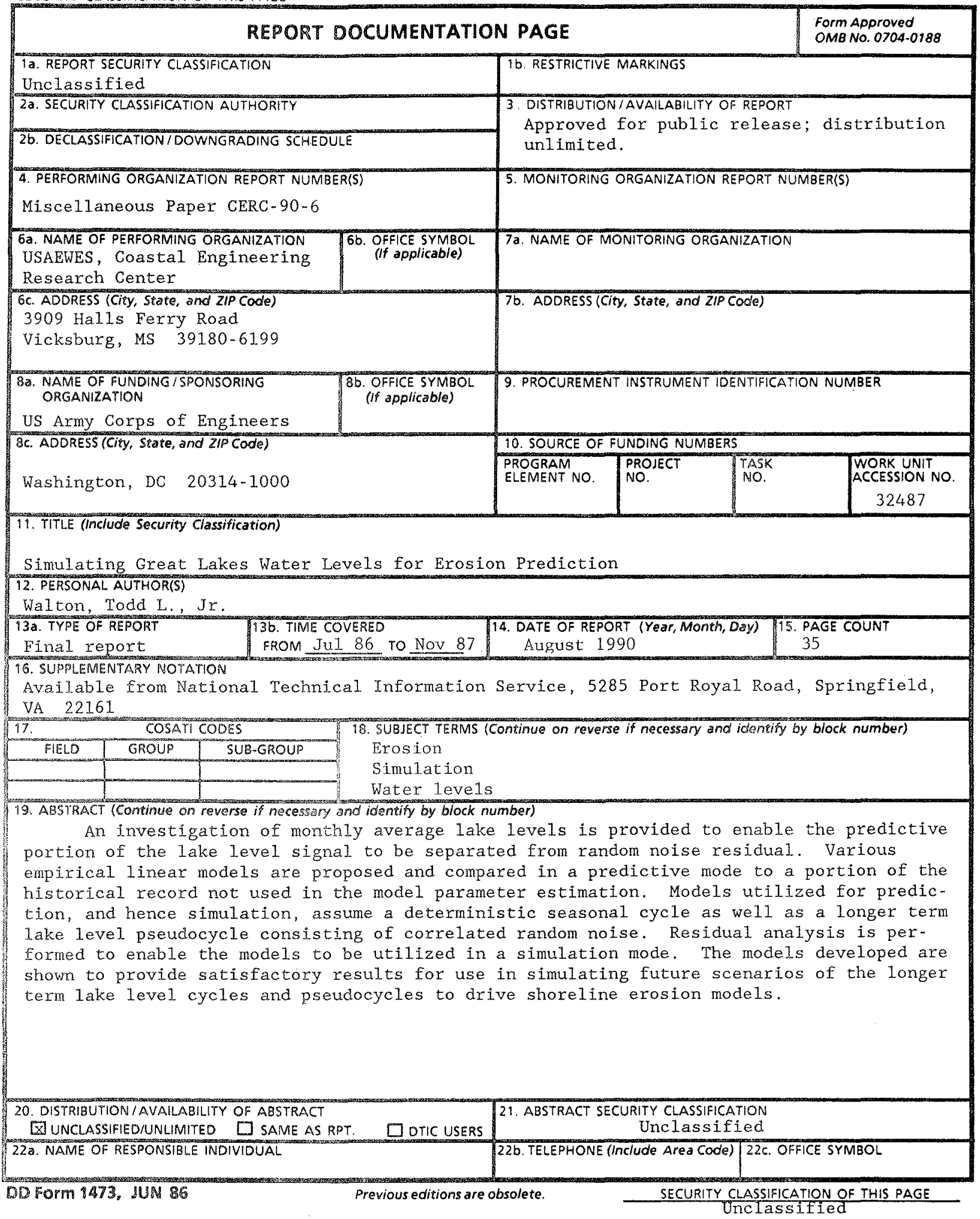




\section{PREFACE}

The investigation described in this report was authorized as part of the Civil Works Research and Development Program by the Headquarters, US Army Corps of Engineers (HQUSACE). This study was conducted by the work unit entitled "Stochastic Coastal Models," Work Unit 32487, under the Shore Protection and Restoration Program at the Coastal Engineering Research Center (CERC) of the US Army Engineer Waterways Experiment Station (WES). Messrs. John H.

Lockhart, Jr., John G. Housley, and James E. Crews were the HQUSACE Technical Monitors. Dr. C. Linwood Vincent is CERC Program Managex.

The study was conducted from July 1986 through November 1987 by Dr. Todd L. Walton, Jr., CERC, under the general supervision of Dr. James R. Houston and Mr. Charles C. Calhoun, Jr., Chief and Assistant Chief, CERC, respectively, and under the direct supervision of $\mathrm{Mr}$. Thomas W. Richardson, Chief, Engineering Development Division, CERC.

Commander and Director of WES during publication of this report was COL Larry B. Fulton, EN. Dr. Robert W. Whalin was Technical Director. 


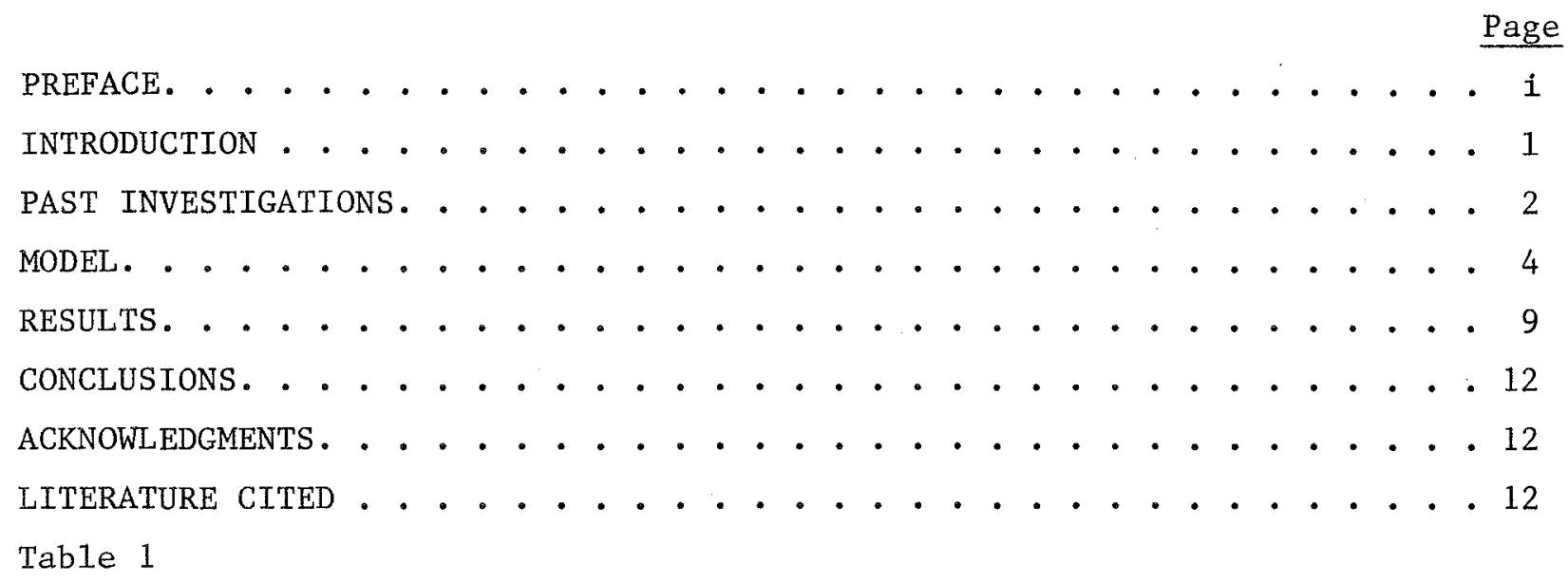

Figures 1-14 


\section{INTRODUCTION}

Considerable debate (CHRYSTAL and MURRAY,1906; MCDONALD,1954; BRUNK,1959;

DECOOK,1961; MEGERIAN,1964; LIU,1970; COHN and ROBINSON,1976; QUINN,1986;

CHANGNON,1987) has been ongoing since the early portion of the twentieth century concerning man's ability to predict potential future periods of time during which lake levels would be at high stages. Storms that occur during these periods of high lake level do considerable damage to shore structures, beaches, bluffs, and lakefront dwellings. Attempts to mitigate erosion and potential flood damage from high lake stages while at the same time improving navigation benefits by prevention of excessive periods of low water levels have resulted in a series of complex water level control regulations on both Lake Superior and Lake Ontario (INTERNATIONAL JOINT COMMISSION,1976) altering natural stages of the lakes to some extent. Additional effects of channel dredging between the lakes, as well as flow diversions to and from the lakes have also altered natural lake stages, but to a lesser degree. The extent of man's infuence on the lakes is subject to wide debate but appears minor compared to nature's cycles or pseudocyles in lake water level. This hypothesis will be investigated in a later portion of this paper for the more recent period of time from 1921 thru 1987.

An ability to forecast future water levels would be useful for optimal control of lake stages but it is also a necessary first step in simulating future water levels for prediction of potential beach erosion that might occur in a major storm. Operational forecast models of lake stages appear to be of a short forecast horizon (DECOOKE and MEGERIAN,1967; CROWLEY,1987) with the apparent belief that, the natural driving force for lake level change being random precipitation, long range ( $>6$ 
months) forecasting would be of limited utility. It is important to note though that any persistence in the data (i.e. high lake levels followed by high lake levels or vice versa) justifies an attempt to extend the forecast horizon for lake stage prediction and hence provide better ability to do realistic simulation of future lake level events. The present paper is an attempt to utilize a recent geophysical digital signal processing algorithm, the Maximum Entropy Method (BURG, 1975) to forecast Great Lake monthly average water levels in an attempt to separate monthly average water level signal informational content from random noise in the time series. By reducing the water level time series to random uncorrelated noise, the potential for simulation of water levels containing the same statistical properities and correlation structure as the original series is realized. The methodology used to do the forecast is shown to provide a forecast horizon well beyond one year in the case of the lower Great Lakes (Superior is intensively regulated and therefore lake level forecasts are very close to actual with little noise in the series).

\section{PAST INVESTIGATIONS}

Various investigators have attempted to predict future cycles of high water in the Great Lakes for the previously mentioned reasons. COHN and ROBINSON (1976) provided a deterministic process Fourier analysis approach to the problem of determining monthly average lake levels with the result that the lake levels followed natural cycles with periods of $1,11,22$, and 36 years. LIU(1970), in a more recent analysis, investigated the spectral shape of the monthly average water levels as well as the probability distributions of monthly average water levels. LIU(1970) found 
that the water levels were approximately Gaussian distributed, but often failing a Chi Square test at a 95 percent significance level. He noted that the series was better fit with a Gram-Charlier probability distribution function which allows for skewness within the data, and he attributed the skewness to possible nonlinear aspects of the hydrological processes involved in lake level forcing functions. As the Chi squared test is a weak test for normality (STEPHENS (1974)), the hypothesis of normality will later be tested with a stronger statistical test, the Kolmogorov-Smirnov test. LIU'S(1970) conclusions concerning the spectral shape of the deseasonalized time series suggested that the lake levels were indeed noise with no apparent true cycles except for the seasonal cycle. An important point not mentioned was that the series was correlated noise, not white noise, hence additional informational content still existed within the series to improve upon future prediction and hence simulation.

YEVJEVICH (1975), in an approach similar to the one being presented here, developed a simulation model for the mean monthly net basin supply for the various lakes, where the net basin supply consists of precipitation, evaporation, groundwater contribution, surface inflow and outflow to the lake. As the net basin supplies were derived indirectly from limited noisy measurements and incorporated additional uncertainty in estimating evaporation and groundwater contribution, the end result was a noisy signal with limited informational content.

The present approach to future water level simulation was to utilize the existing data base on Great Lakes water levels (NATIONAL OCEANIC and ATMOSPHERIC ADMINISTRATION,1987) due to the fact the gage water levels present an accurately measured time series relatively uncontaminated by man's lack of understanding of the natural physical processes of precipitation and evaporation. 


\section{MODEL}

The model proposed here is a hybrid model composed of a seasonal component combined with a linear autoregressive model, the Maximum Entropy Method model (BURG,1975). This model will be shown to produce a reasonable forecast and be capable of reducing the original monthly average water level to random uncorrelated noise. The period of record used to test the model in a forecast mode was 1921 thru 1987. Although Great Lakes monthly average water levels date back to the 1860 's prior to regulation of Lake Superior, the control plan and operating rules initiated in 1921 on Lake Superior appear to have modified the lake level variations on the lower Great Lakes (INTERNATIONAL JOINT COMMISSION,1975). Figures 1 through 3 show the monthly average water levels for gages on Lakes Michigan-Huron (5014), Lake Erie (3063), and for Lake Ontario (2030) for the period 1921 thru 1987. Autocorrelation plots for the same series are shown in Figures 4 through 6 and show the high persistence along with seasonal correlation within the lake level time series. This persistance is marked by not only a strong correlation between months but also a strong correlation at yearly levels ( lag $=12$ months). This particular structure with correlation at seasonal (in this case yearly lags) is suggestive of a seasonal trend (eicher nonstationary random, stationary random, or deterministic) in the data and can be handled by a variety of methods.

If the seasonal trend is assumed to be of a nonstationary nature (i.e. does not seek a seasonal time dependent level), then the best approach to deseasonalizing the data is via seasonal differencing, in the case of monthly average data this involves differencing at lag 12 . In terms of a linear filter representation, this type of 
deseasonalizing filter is given as:

$Z(t)=\left(1-B^{s}\right) X(t)=\nabla_{s} X(t)$

where $\mathrm{X}(\mathrm{t})$ is the original series, $\mathrm{Z}(\mathrm{t})$ is the deseasonalized series by this approach, and $B^{s}$ with $\mathrm{s}=12$ is a backwards lag 12 operator (i.e. see BOX and JENKINS (1976)). The term $\left(1-B^{12}\right)=\nabla_{12}$ is a linear difference operator or filter of order 1 and degree 12 on the data. BOX and JENKINS (1976) are proponents of this approach to handling seasonal correlation structure in the data and recommend seasonal differencing to reduce the data to stationarity. A particular problem with this approach is that such differencing removes a stationary mean level of the process and hence forces a nonstationarity into the data regardless of whether the data are nonstationary or not. This type of filter is equivalent to an assumed random walk (at seasonal lag) model assumption. Although nonstationarity may be present in long geophysical records such as the ones analyzed here due to long term climatic changes or man made changes (i.e. flow diversions, channel deepening, or urbanization effecting runof changes), such changes should not be assumed a priori without physical justification.

A second method of evaluating the seasonal trend and deseasonalizing the model is to utilize either an autoregressive AR or autoregressive/moving average ARMA seasonal filter as given by:

$Z(t)=\frac{A_{s}\left(B^{s}\right)}{M_{s}\left(B^{s}\right)} X(t)$

where $A_{s}\left(B_{s}\right)$ is a seasonal autoregressive polynomial of $\mathrm{B}$ with order $\mathrm{s}(=12$ in present case) and constant coefficients, and $M_{s}\left(B^{s}\right)$ is a seasonal moving average polynomial of B with order s and constant coefficients. Assuming the roots of the 
autoregressive polynomial are all less than one (i.e. inside the unit circle in the complex plane) is equivalent to assuming stationarity. BOX and JENKINS (1976) are also proponents of this approach to modeling and recommend deseasonalizing of this type in conjunction with similar techniques (i.e. ARMA models) for analysis of the deseasonalized series. When applying the system of filters as given in Eq. 2 along with a stationary data filter given in general form as:

$W(t)=\frac{A(B)}{M(B)} Z(t)$

where $W(t)$ represents a white noise (innovation) term and the roots of the autoregressive polynomial are less than absolute value one, the model becomes what BOX and JENKINS(1976) refer to as a seasonal multiplicative model. A possible criticism of the multiplicative seasonal model is that there is no physical reason to believe that a white noise process $\mathrm{W}(\mathrm{t})$ should be influenced by antecedent conditions at a lag period s. This particular model was used in the investigation of lake levels and will be discussed further below.

A third approach to the deseasonalization of the level data is provided by standardization of the seasonal series as given by:

$Z(t)=\frac{X(t)-m(t)}{s_{d}(t)}$

where $m(t)$ is the estimated time varying mean value of $X(t)$, in the present case monthly averages, and $s_{d}(t)$ is the time varying standard deviation of $\mathrm{X}(\mathrm{t})$ (i.e. monthly indexed standard deviation). This particular approach is well adapted to heteroscedastic data of the type seen in hydrologic time series as noted by KASHYAP and RAO(1976). After deseasonalization by this approach, the data typically assume a stationary form to which a stationary type of model such as an AR or ARMA 
model can be fit. For parsimony of terms, the time varying monthly mean and variance terms can be fit by discrete Fourier series with only those coefficients retained which show significance. In the present analysis, this standardization method of deseasonalization was used but the seasonal coefficients were used (12 means and 12 standard deviations) rather than providing a Fourier series fit to the seasonal means and variances.

Three methods were used to assess whether the assumption of stationarity was reasonable for the water level monthly average series during the period of record from 1921-1987. The first test used was a runs test as suggested in BENDAT and PIERSOL(1971), which consists of counting the number of runs about the mean of the process for the mean square value of equal segments of record. This particular test does not require that the seasonal trend be removed prior to testing as long as the fundamental period is short compared to the averaging time used to compute sample values, therefore the series was not deseasonalized prior to testing. The hypothesis that the data were random stationary at a 5 percent significance level was tested and accepted for all three lake level series.

Prior to the remaining two methods for testing stationarity, the data were deseasonalized via standardization with monthly means and variances as noted in previous paragraphs. The second method used to assess stationarity was to split each series into two segiments, beginning 1921-1954 and ending 1955-1987, and compare both autocorrelation functions and raw spectrums of the data for consistency throughout time. This method also did not provide any evidence for nonstationarity in the series.

The third method utilized for checking the stationarity assumption was to segiment 
the series as in the method above and compute autoregressive parameters for the series utilizing the BURG(1967) Maximum Entropy Method algorithm. Results of this particular test for a two parameter autoregressive model test are given in Table 1. Although differences in the parameter estimates between the first half 1921-1954 and last half 1955-1987 of the series for the three gages tested are noted, it would appear that such differences are of minor significance. This observation is based on the fact that the first autoregressive parameter estimate varies less than 10 percent and averages only 5 percent difference between the two record halves.

As noted in the previous paragraph, the water level time series for the lower lakes did not show evidence for nonstationary after 1921 (the year in which major regulation of Lake Superior was initiated) in any of the nonstationary tests. This analysis suggests that man's intervention on the lakes has not seriously altered the natural levels of the lower Great Lakes at least in the period since 1921. It is on the basis of this preliminary data checking that a univariate model for lake level simulation is based. As the series appears to be generally stationary, a constant parameter model will be assumed sufficient for the generation of a forecast model and hence for simulating future scenerios of lake levels.

Two models for the lake level simulation were used. The first model discussed is that of a deseasonalizing filter as given by Eq. 4 followed by the BURG(1967) Maximum Entropy Method (MEM algorithm utilizing the Akaike Information Criterion (AIC) proposed by AKAIKE(1974) for model order fitting of the final model for each lake series. In the case of the BURG(1967) MEM algorithm, the AIC criterion is equivalent to AKAIKE(1972) Final Prediction Error (FPE) and is therefore noted as such. The reason for utilization of the BURG(1967) MEM algorithm is based 
on the preanalysis of the spectral shapes of the deseasonalized lake level spectra which were investigated both here and previously by LIU(1970) and are suggestive of autoregressive (all pole) spectra. The low frequency content of the signals also suggested that low order models might be reasonable for all series. This fact agreed with the FPE criterion which had a minimum final prediction error for model order two in all three lake level series investigated. An example of the FPE criterion error versus the model order is given in Figure 7 which shows a considerable reduction in error for models beyond an $\mathrm{AR}(1)$ but implies that the error reaches a broad plateau beyond a second order model suggesting that any low order model (two or more) might be used. In view of the desirable aspect of parsimony, the minimal FPE model order two was used for this model. The final filter provided by this model is a combination of Eq. 4 followed by Eq. 3 with $M(B)=1.0$. Residual testing of this model will be investigated below.

A second model investigated was of the seasonal multiplicative type as provided via a filter consisting of a seasonal filter of the type in Eq. 2 with $M_{s}\left(B^{s}\right)=1.0$ and one seasonal autoregressive parameter, followed by a stationary filter of Eq. 3 form with $M(B)=1.0$ and two normal autoregressive parameters. In this case the Eq. 3 filter was the BURG(1967) MEM algorithm as in Model 1. Residuals from this model were also tested and will be discussed below.

\section{RESULTS}

A meaningful test of a model is provided by comparing a portion of the time history of the model with a predictive forecast during a future period of the time series and 
comparing model forecast with what really happened during the same period of time. This approach to investigating model validity was used for the three lake series with the historical period of record from 1921-1964. The period of forecast used was from 1965-1967. It is noted from Figures 1-3 that the year 1964 occurred during a period of prolonged low water level on the lake and appeared to be a turning point after which lake levels began to get higher. Forecast series for the three lakes for Model 1, the standardized data model, based on the master gage level data for the lakes are given in Figures 8-10. A forecast series for the same time period utilizing Model 2, a seasonal multiplicative model, is given in Figure 11. As can be seen in Figures 8-11, both models show rising water levels as noted in nature and appear to track the historical record within reason (i.e. realizing that the noise in the series is filtered out). Model 1 appears to provide a more reasonable approach to fitting of the seasonal cycle as seen in the historical record, although the overall level of the series seems to be followed more closely by Model 2 (shown for the case of gage 5014). The seasonal cycle appears so prevalent within the data that subjectively, at least, the standardized seasonal reduction model appears to model nature more realistically.

Residuals from both models were tested for randomness and for probability distribution of residual for future simulation purposes. The original series were tested for normality and found to be reasonably normal via previous work (LIU, 1970), and within the present testing framework by a Kolmogrov- Smirnov test (STEPHENS (1974)). The hypothesis of normality was not rejected with the Kolmogrov-Smirnov test for any of the lake level series at a five percent significance level. Based on this result, a normal distribution was expected for the residuals since a Gaussian process 
acted upon by a linear filter returns a Gaussian process. This fact was verified by a check of the residuals from the two models. Residuals from both models are not significantly different from Gaussian noise as determined via the Kolmogrov-Smirnov test at a five percent significance level. An example of the residual fit to a Gaussian distribution is provided in Figure 12 where the residuals from Model 1 with a two parameter fit to gage 5014 water levels is plotted on normal probability paper.

For simulation purposes (and forecasting purposes), it is most desirable that the model provide a transformation of the correlated series to white noise. A final check on any model should investigate whether the residuals in fact comply with a white noise assumption typically assumed for simulation purposes. The autocorrelation for the residuals from model 1 for the second order autoregressive (MEM) model is provided in Figure 13 along with confidence limits for an assumption of white noise at a five percent significance level. As can be seen in this figure, the assumption that the residuals are white noise is well justified. Another way of testing this same assumption is via an integrated periodogram. An integrated periodogram of white noise follows closely to a straight line on a frequency plot with the form $I=a f$, where "I" is a measure of the integrated spectral energy and "f" is frequency. The constant "a" depends on the units. Figure 14 is an example of integrated periodogram for the residuals from model 1 with a second order fit to the lake level data of gage 5014. Kolmogrov- Smirnov seventy-five and ninety-five percent confidence bounds have been placed on the plot from which it can be seen that the residuals from the model do indeed fulfill the desired assumption of white noise. Similar plots for gages 3063 and 2030 of the residual autocorrelations and integrated periodograms for both models discussed previously are not shown here but provide similar conclusions (i.e., 
the residual series has been reduced to white noise).

\section{CONCLUSIONS}

Two models have been developed for use in simulating future scenerios of (mon thly) average water levels to which random storms can be superimposed for a full description of the water level during an erosion event or a future scenerio of erosion events. The models can be utilized in conjunction with dynamic erosion models (KRAUS and LARSON (1988)) and simulated storm sequences to determine erosion event versus return period. The models developed have been shown to reasonably predict into the future with the limited amount of information present in the signal of the time series. The models have reduced the correlated seasonal fluctuation of water level to a white noise (uncorrelated) series therefore showing that the maximum amount of information within the series has been extracted for utilization in simulating future scenerios of water level averages.

\section{ACKNOWLEDGMENTS}

The work presented herein was conducted under the Predictive Models to Assess Erosion Mitigation Methods work unit of the Shore Protection and Restoration

Program, United States Army Corps of Engineers, Coastal Engineering Research Center, Waterways Experiment Station. Permission was granted by the Chief of Engineers to publish this information.

LITERATURE CITED

AKAIKE,H.,1972. Use of an Information Theoretic Quantity for Statistical Model 
Identification, Proceedings of the 5th International Conference on System Sciences, Honolulu, Hawaii,249-250.

AKAIKE,H.,1974. A New Look at the Statistical Model Identification, IEEE Transactions on Automatic Control, AS- 19, 6, 716-723.

BENDAT,J.S. and PIERSOL,A.G.,1971. Random Data, Analysis and Measurement Procedures, John Wiley and Sons Publishing Company,407p.

BOX,G.E.P. and JENKINS,G.M.,1976. Time Series Analysis, Forecasting, and Control, Holden-Day Pub. Company,575p.

BRUNK,I.W.,1959. Precipitation and the Levels of Lake Michigan-Huron, Journal Geophysical Research, 64, 1591-1595.

BURG,J.P.,1967. Maximum Entropy Spectral Analysis, Proceedings of the 37th Meeting,Society of Exploration Geophysicists, 34-41.

CHANGNON,S.A.JR.,1987. Climate Fluctuations and Record High Levels of Lake Michigan, Journal of the American Meteorological Society, 68(11), 1394-1401.

CHRYSTAL,G. and MURRAY, J.,1906. An Investigation of the Seiches of Loch Earn by the Scottish Lake Survey, Transactions of the Royal Society,Edinburgh, $45,361-396$.

COHN,B.P. and ROBINSON, J.E.,1976. A Forecast Model for Great Lakes Water Levels, Journal of Geology,84, 455-465.

CROLEY,T.E., 1987. Near Real-Time Forecasting of Large Lake Supplies, Joural of Water Resources Planning and Management, American Society of Civil Engineers, 113(6), 810- 823 .

DECOOKE,B.G.,1961. Forecasting Great Lakes Levels, Great Lakes Research Division Publication 7, 79-84.

DECOOKE,B.G. and MEGERIAN,E., 1967. Forecasting the Levels of the Great Lakes, Journal of Water Resources Research, 3(2), 397-403.

INTERNATIONAL JOINT COMISSION,1976. Further Regulation of the Great Lakes, 96p.

KRAUS,N.C., and LARSON,M.,1988. Prediction of Initial Profile Adjustment of Nourished Beaches to Wave Action, Proceedings of the Beach Preservation Technology Conference, American Society of Beach Preservation Association,(to be published).

KASHYAP,R.L. and RAO,A.R., 1976. Dynamic Stochastic Models from Empirical Data, Academic Press, 330p.

LIU,P.C.,1970. Statistics of Great Lake Levels, Proceedings of the 13th Conference on Great Lakes Research, 360-368. 
MCDONALD,W.E.,1954. Variation in Great Lakes Levels in Relation to Engineering Problems, Proceedings of the 4th Conference on Coastal Engineering, American Society of Civil Engineers, 249-257.

MEGERIAN,E.,1964. Forecasting Great Lakes Levels Second through Sixth Month, Great Lakes Research Division Publication 11, 238-252.

NATIONAL OCEANIC AND ATMOSPHERIC ADMINISTRATION, National Ocean Survey, 1987. Great Lakes Water Levels,1860- 1985, U.S. Government Printing Office, .

QUINN,F.,1986. Causes and Consequences of the Record High 1985 Great Lakes Water Levels, Conference on Climate and Water Management, American Meteorology Society, 281-284.

STEPHENS,M.,1974. E.D.F. Statistics for Goodness of Fit, Journal of the American Statistical Association, 69, 730-737.

YEVJEVICH, V.,1975. Generation of Hydrologic Samples, Case Study of the Great Lakes, Hydrology Paper 72, 39p., Colorado State University, Fort Collins, Colorado. 
Table 1

Parameter Estimation Comparison

\begin{tabular}{lll}
\hline Gage Number & \multicolumn{2}{c}{ Perlod of Record } \\
\cline { 2 - 3 } 5014 & $\frac{1921-1954}{1.430,-.440}$ & $\frac{1955-1987}{1.414,-.422}$ \\
3063 & $1.264,-.295$ & $1.149,-.167$ \\
2030 & $1.399,-.431$ & $1.319,-.395$
\end{tabular}

Note: Parameters listed are the first and second autoregressive parameter estimates. 


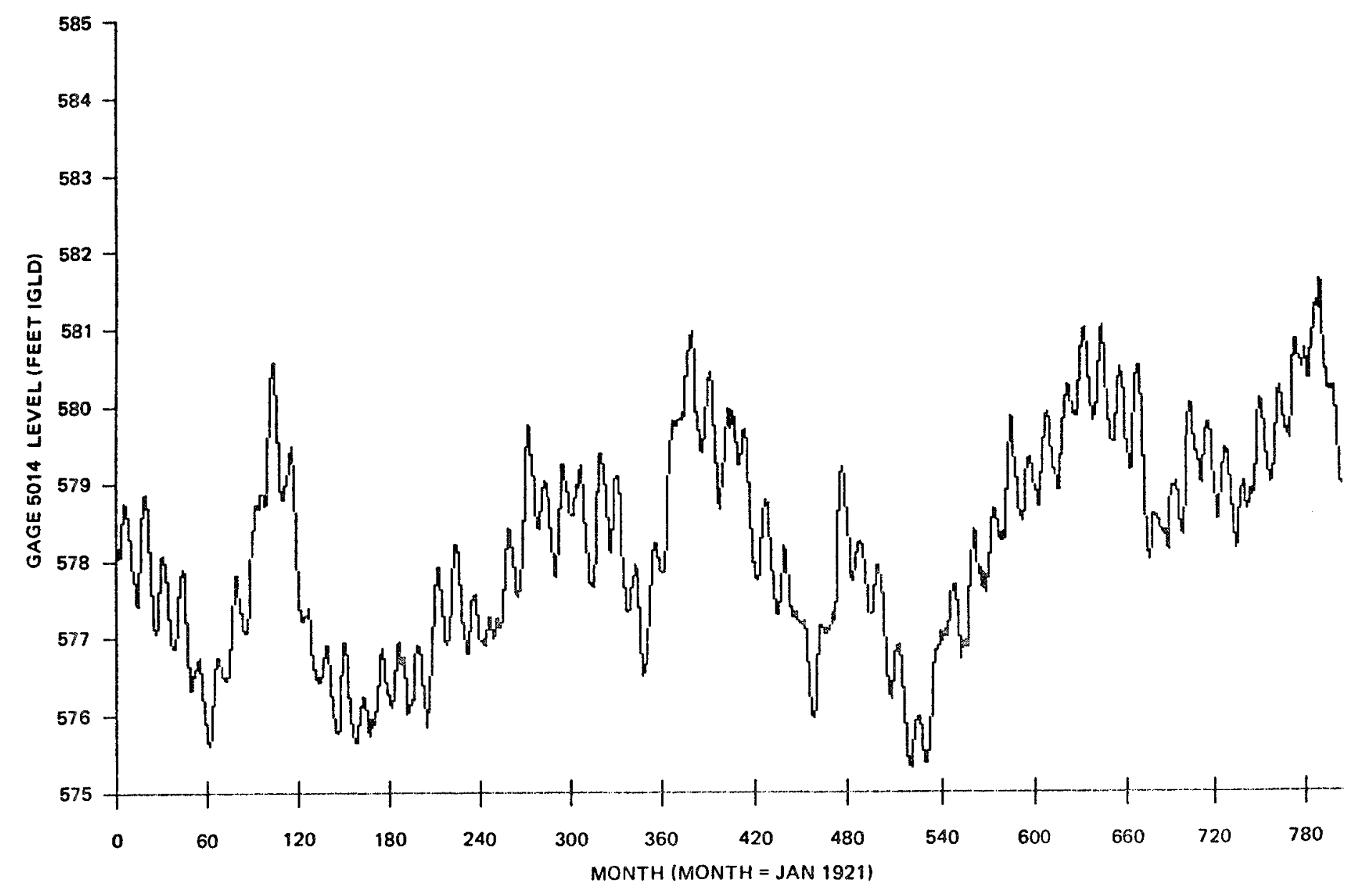

Figure 1. Monthly average water levels - gage 5014 


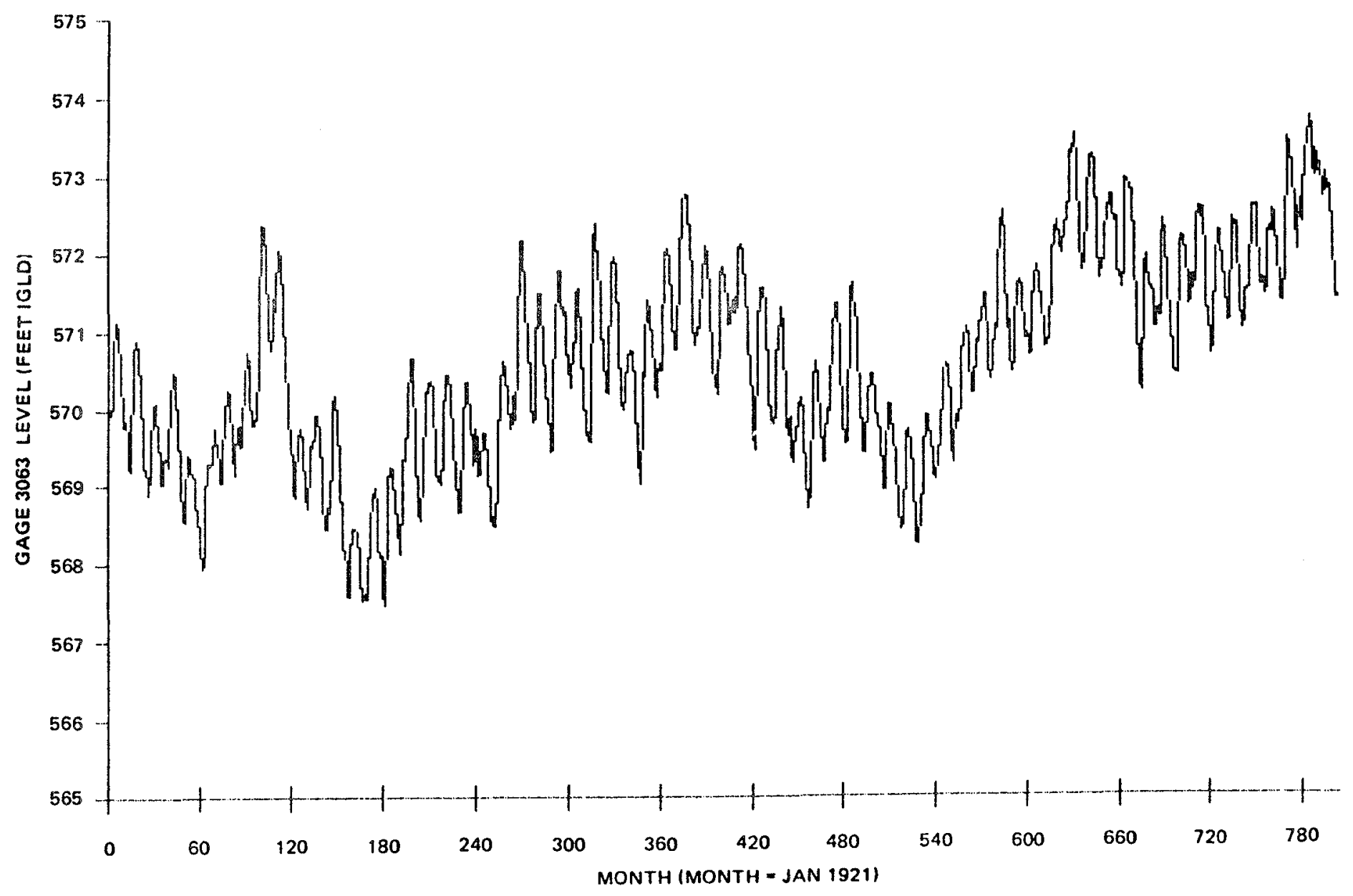

Figure 2. Monthly average water level - gage 3063 


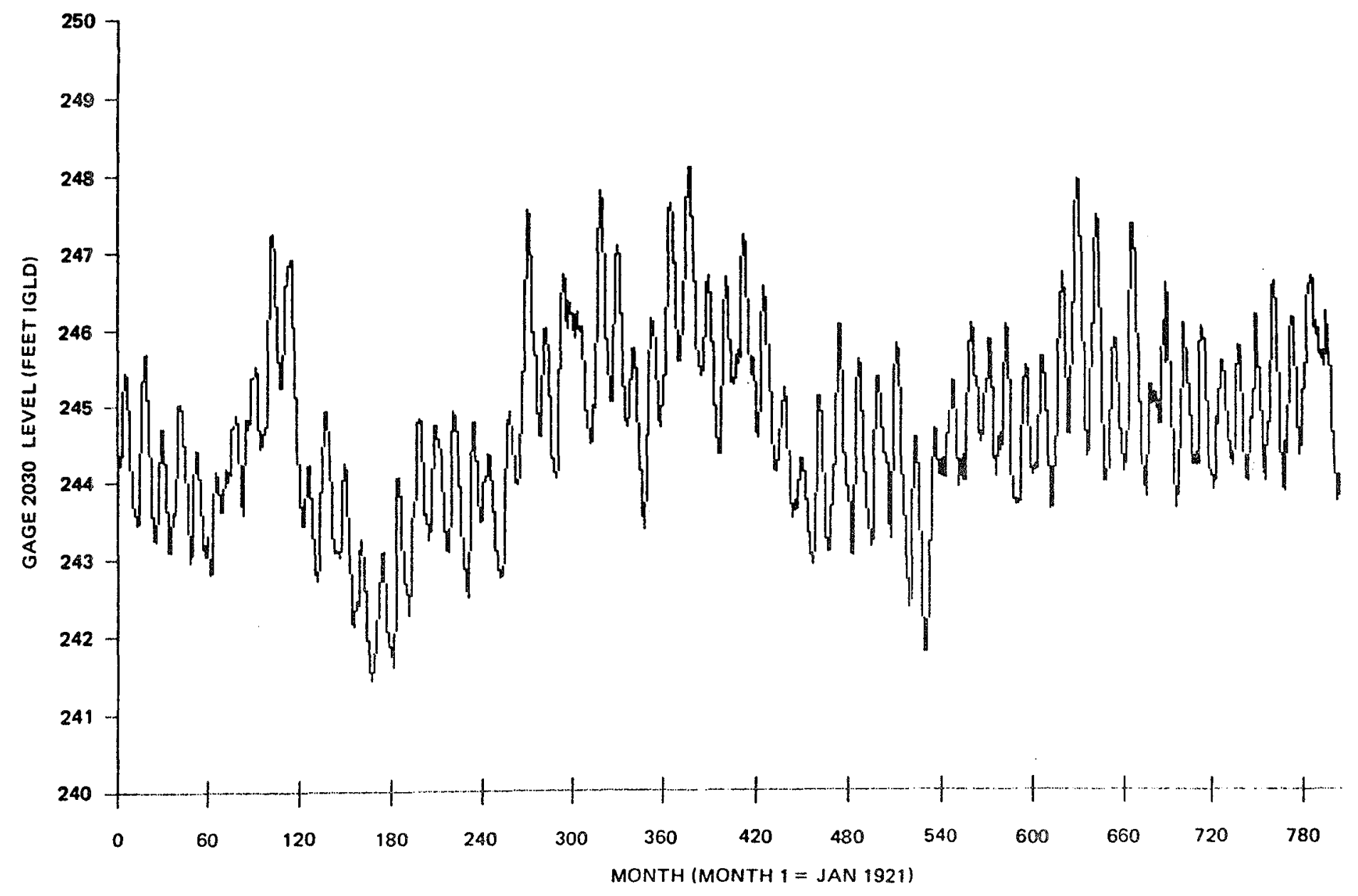

Figure 3. Monthly average water level - gage 2030 


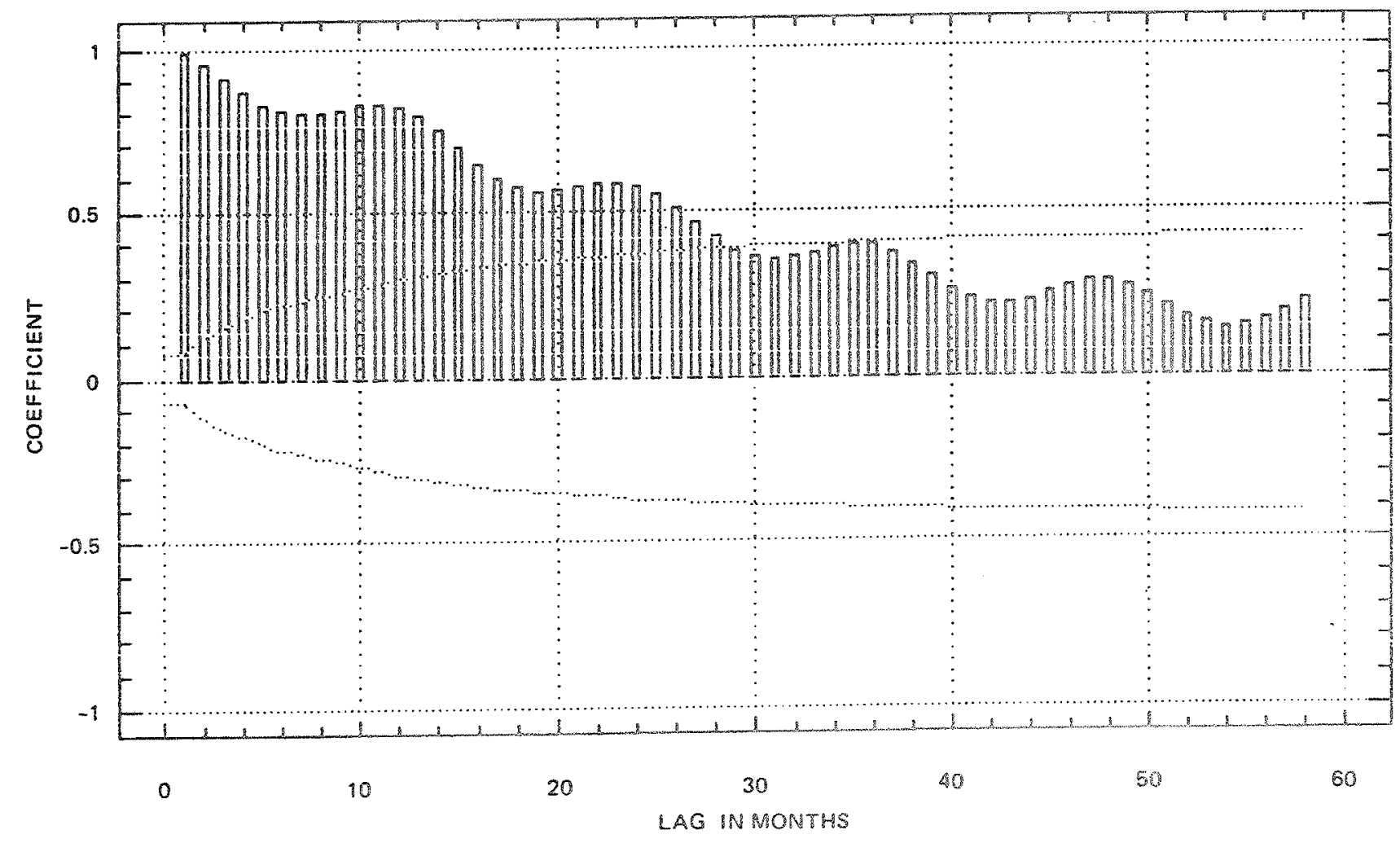

Figure 4. Arto coprelation plot - gage 5014 water levals 


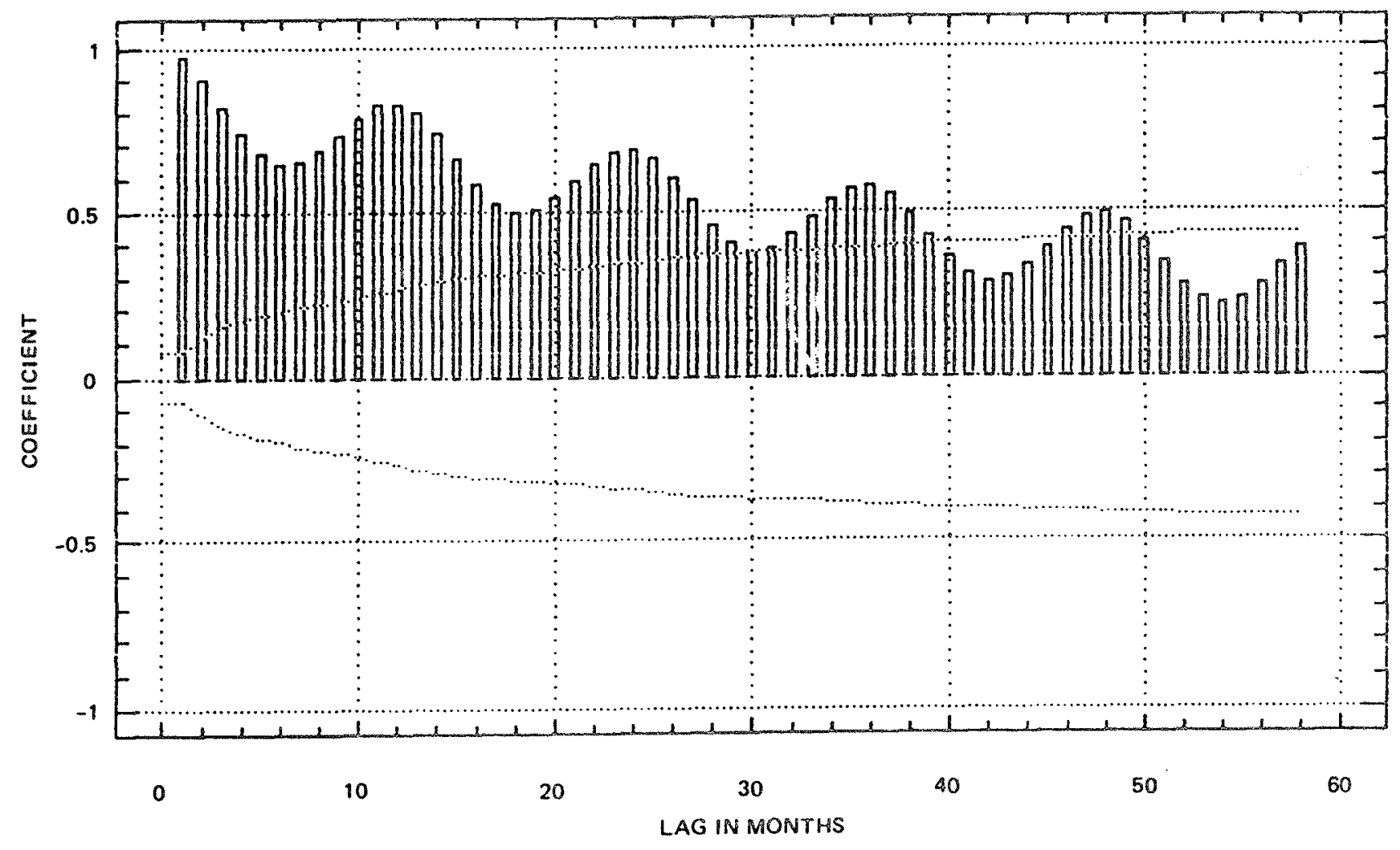

Figure 5. Auto correlation plot - gage 3063 water levels 


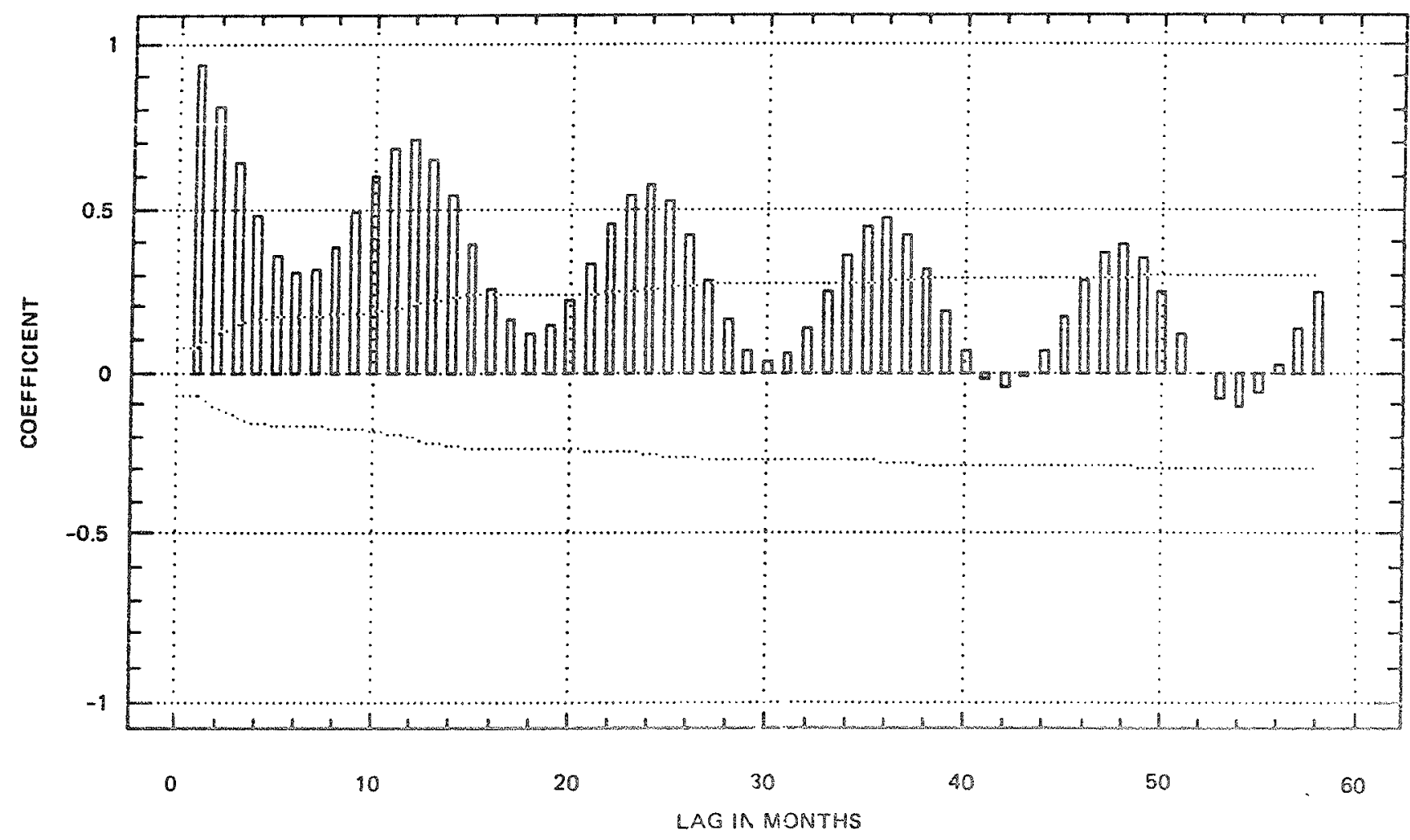

Figure 6. Auto correlation plot - gage 2030 water levels 
GAGE 5014

1921-1986

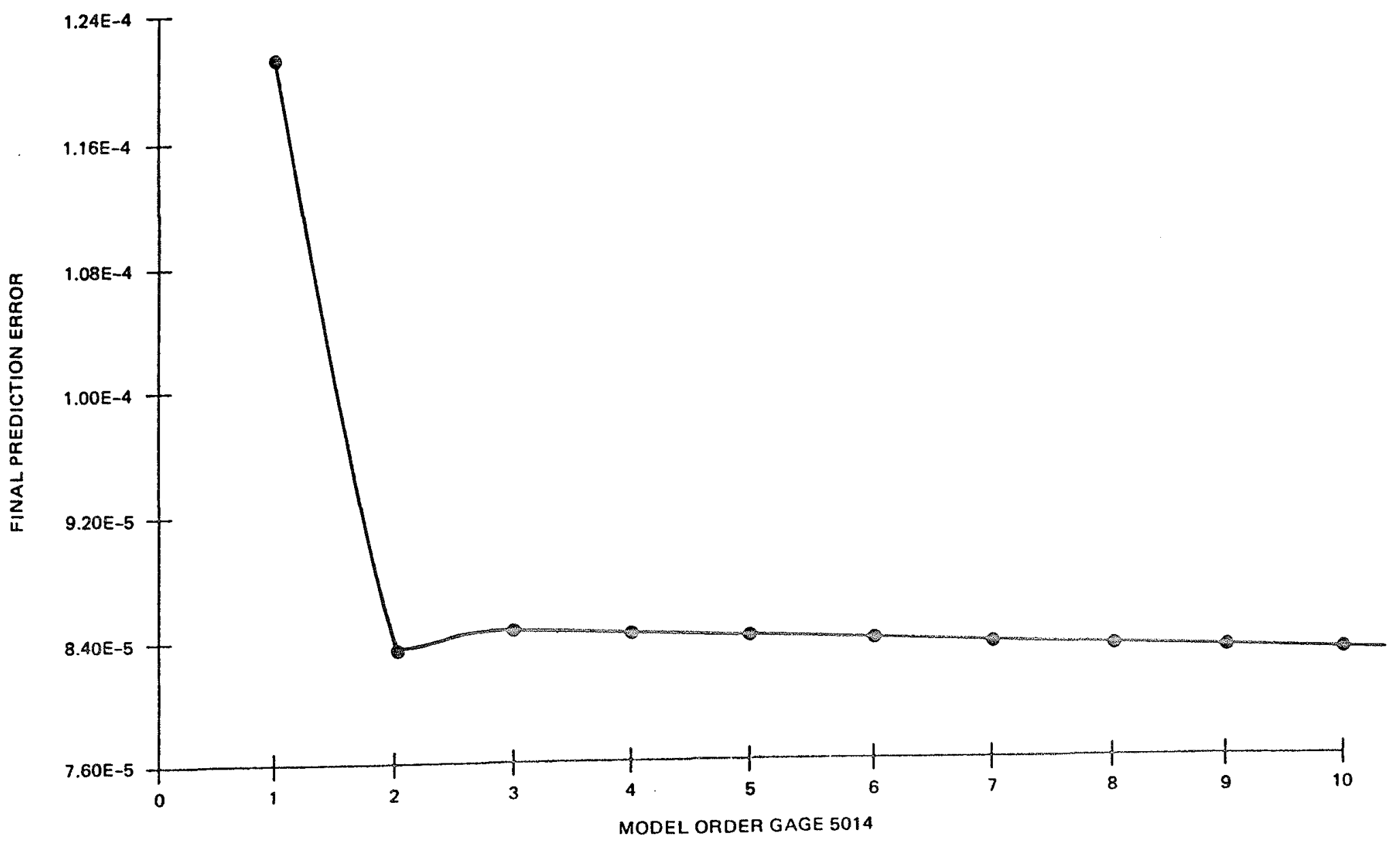

Figure 7. Final prediction orior for gage 5014 AR model 


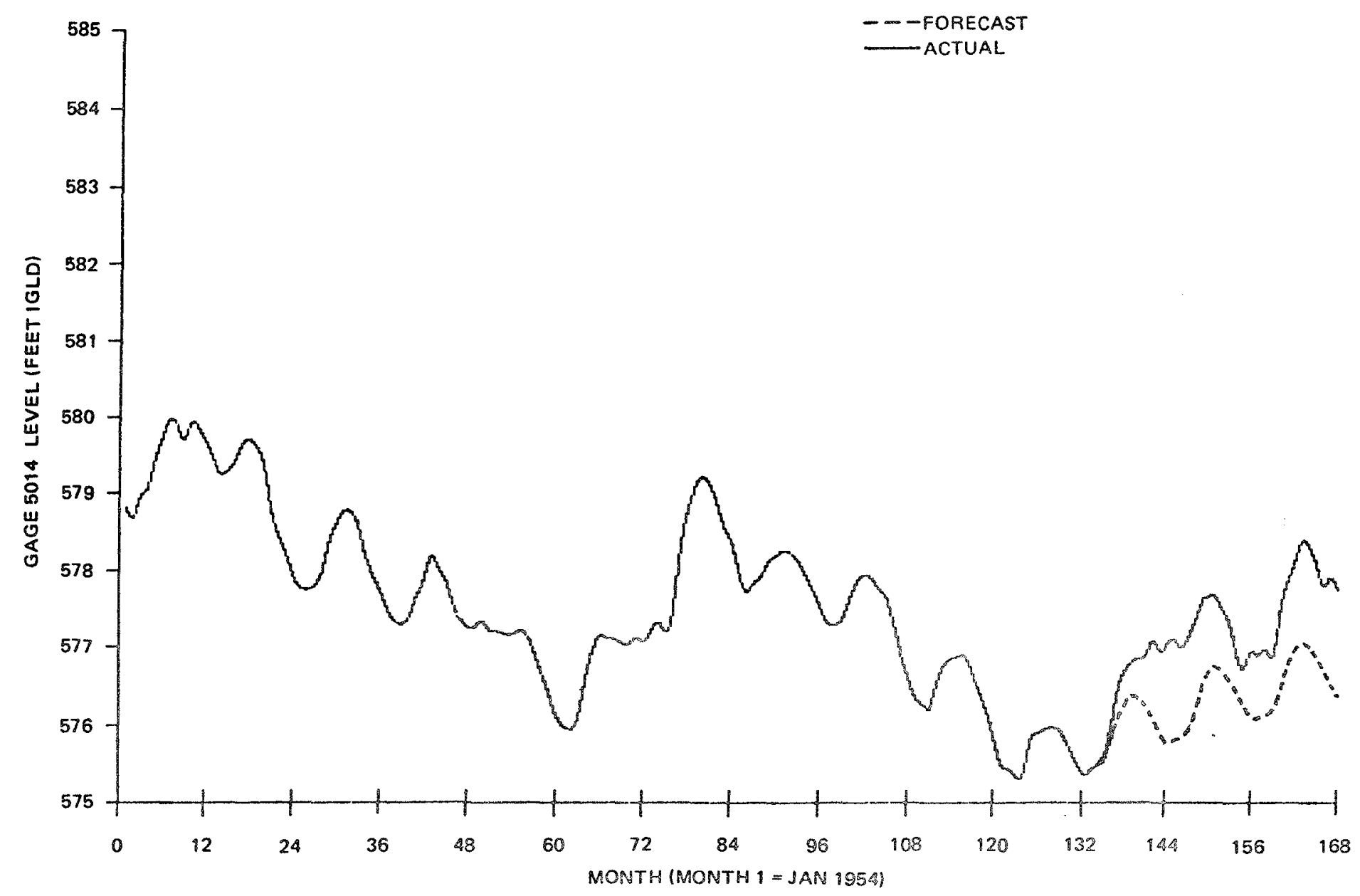

Figure 8. Model forecast - gage 5014 AR(2) modelo 


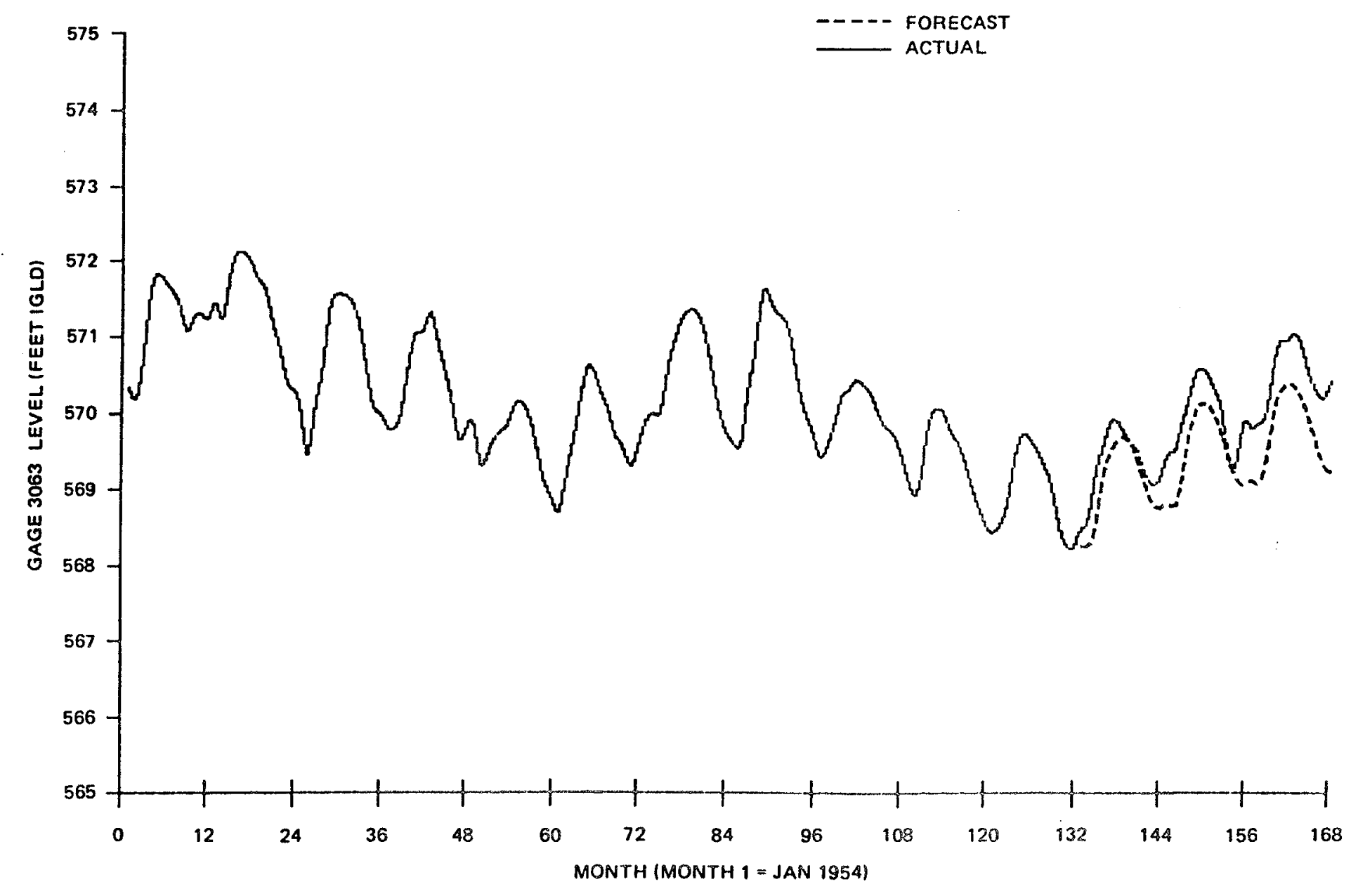

Figure 9. Model forecast - gage 3063 AR(2) model. 


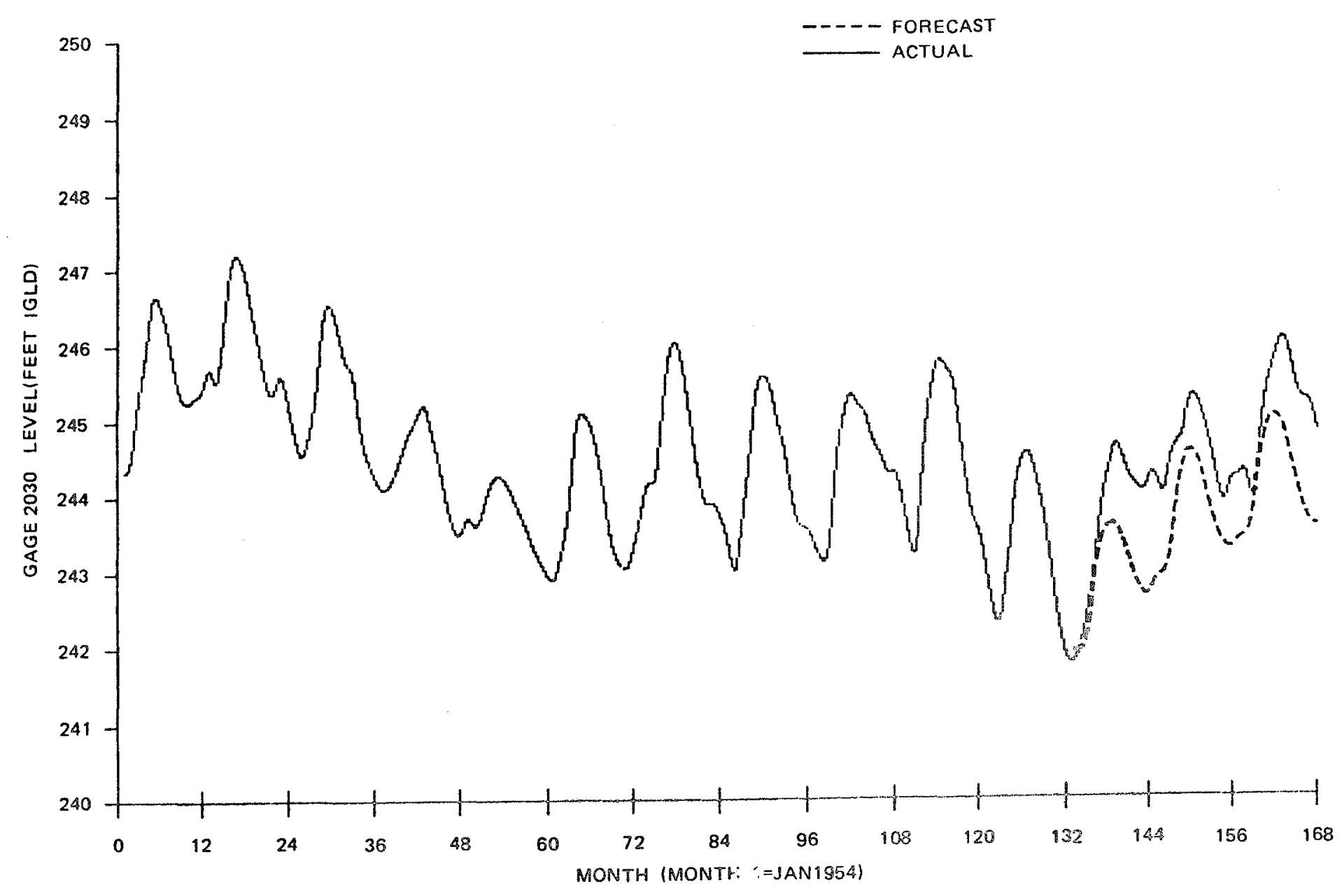

Figure 10. Model forecast - gage 2030 AR(2) model. 


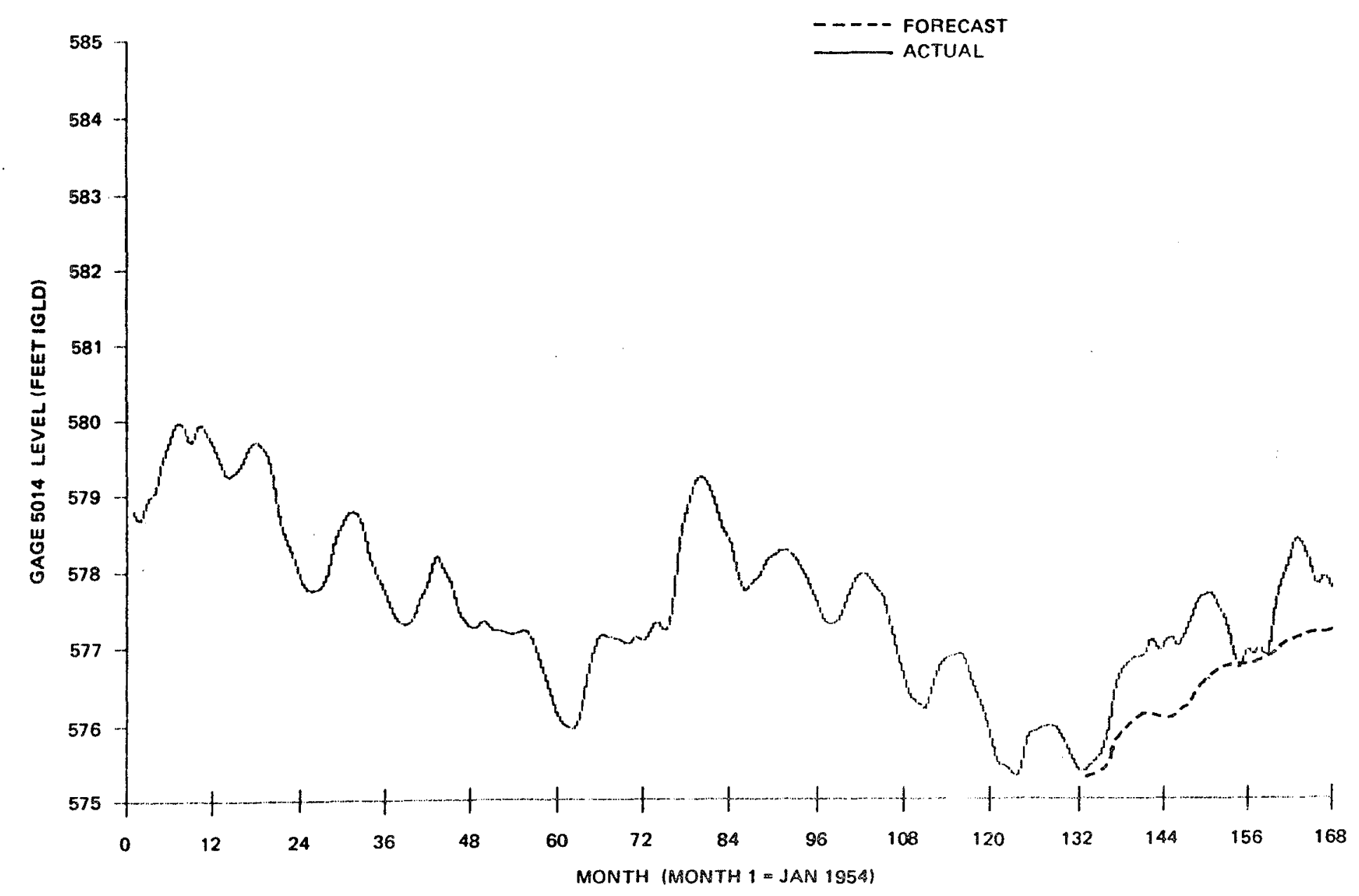

Figure 11. Seasonal multiplicative model forecast - gage 5014. 


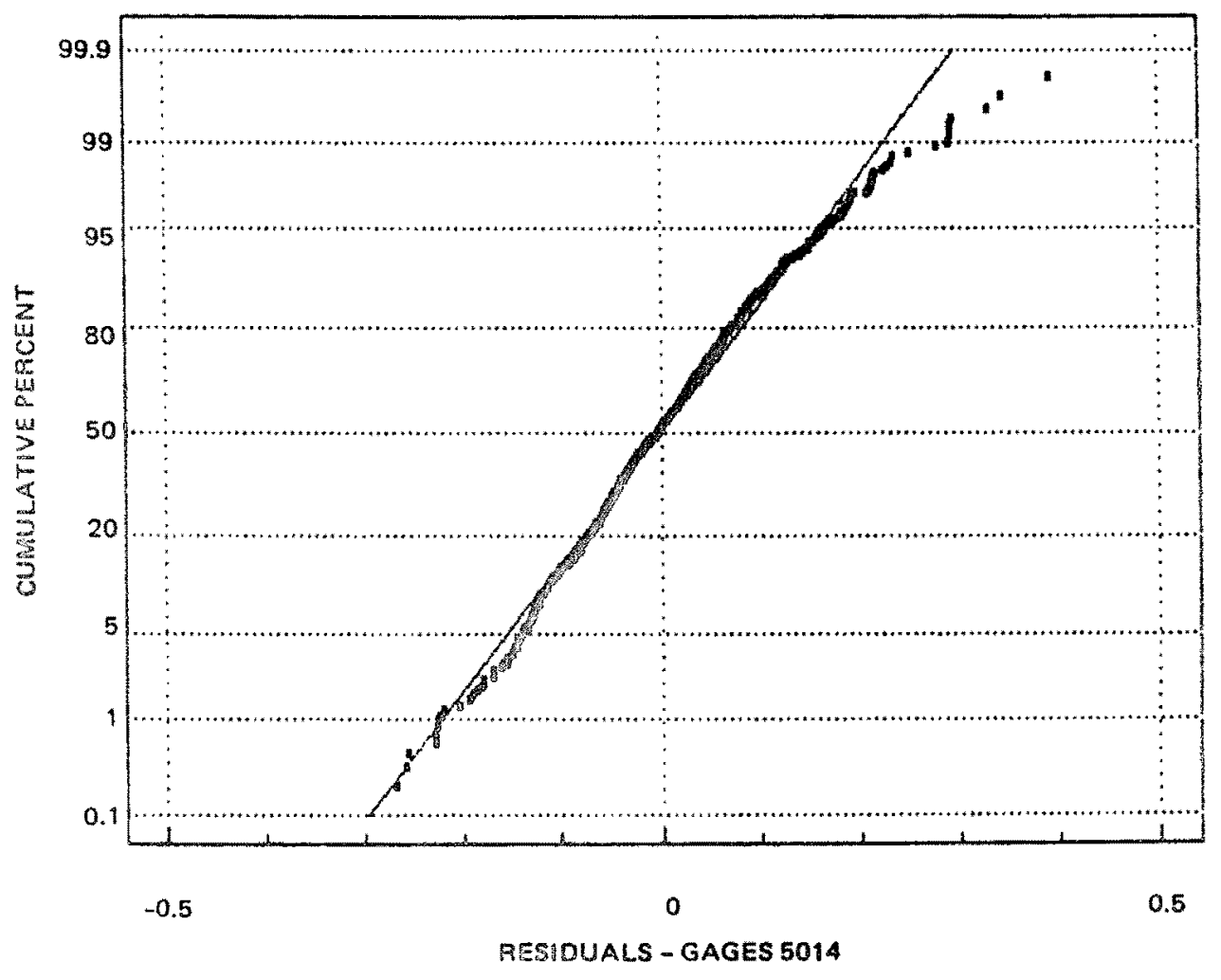

Figure 12. Normal plot of residuals from gage $50 / 4$. 


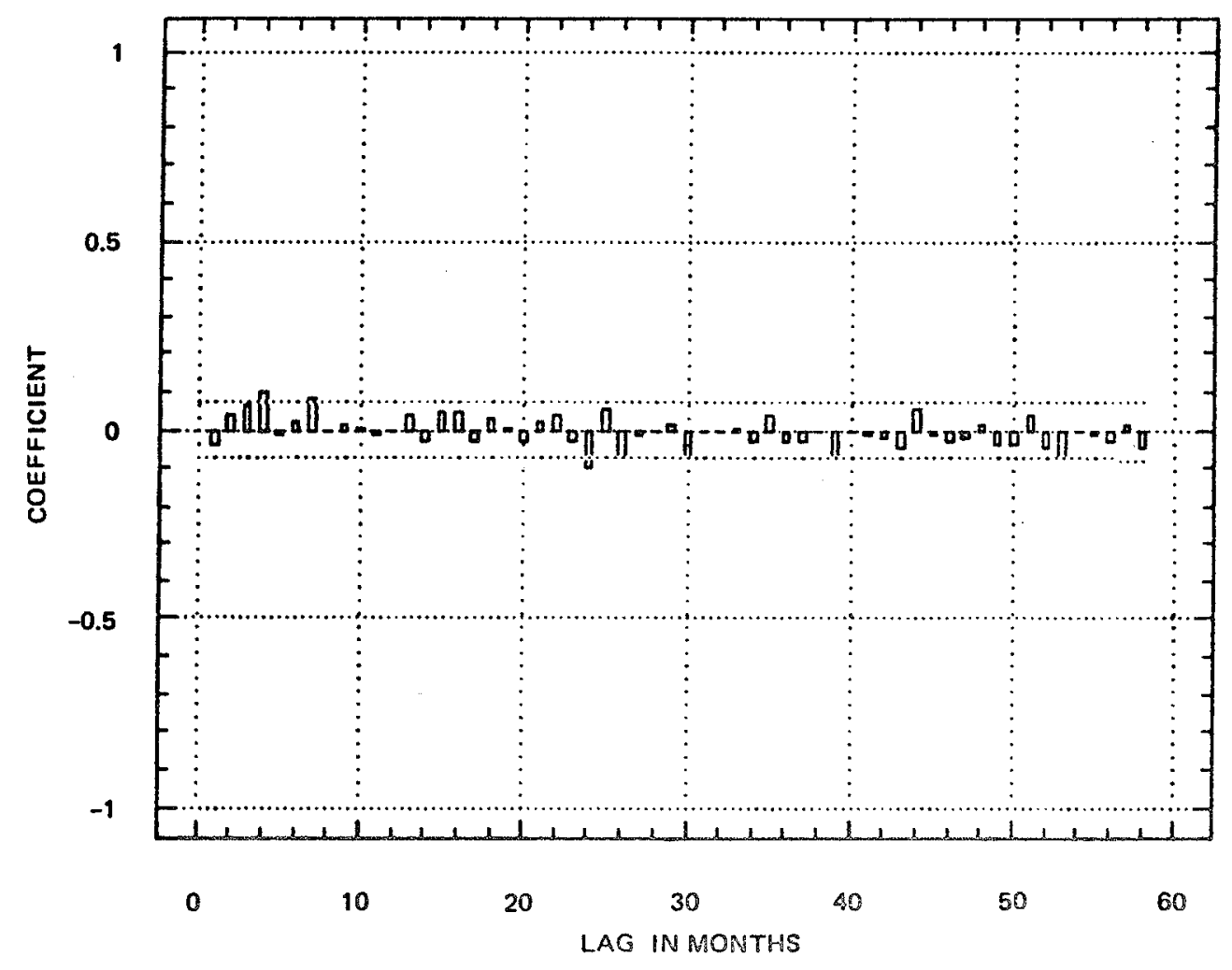

Figure 13. Autocorrelation plot of residuals from gage 5014. 


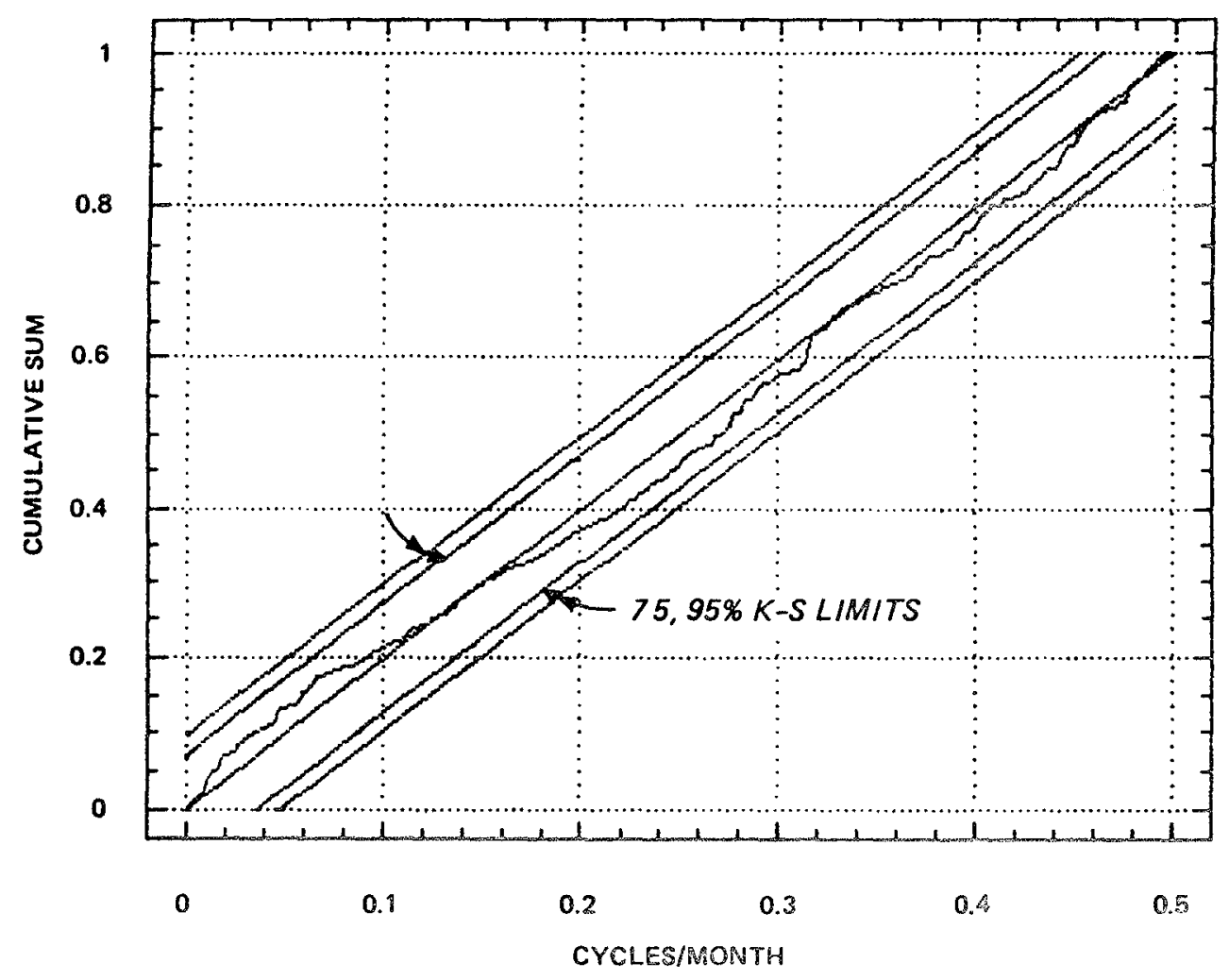

Figure 14. Integrated periodogram of residuals from gage 5014. 